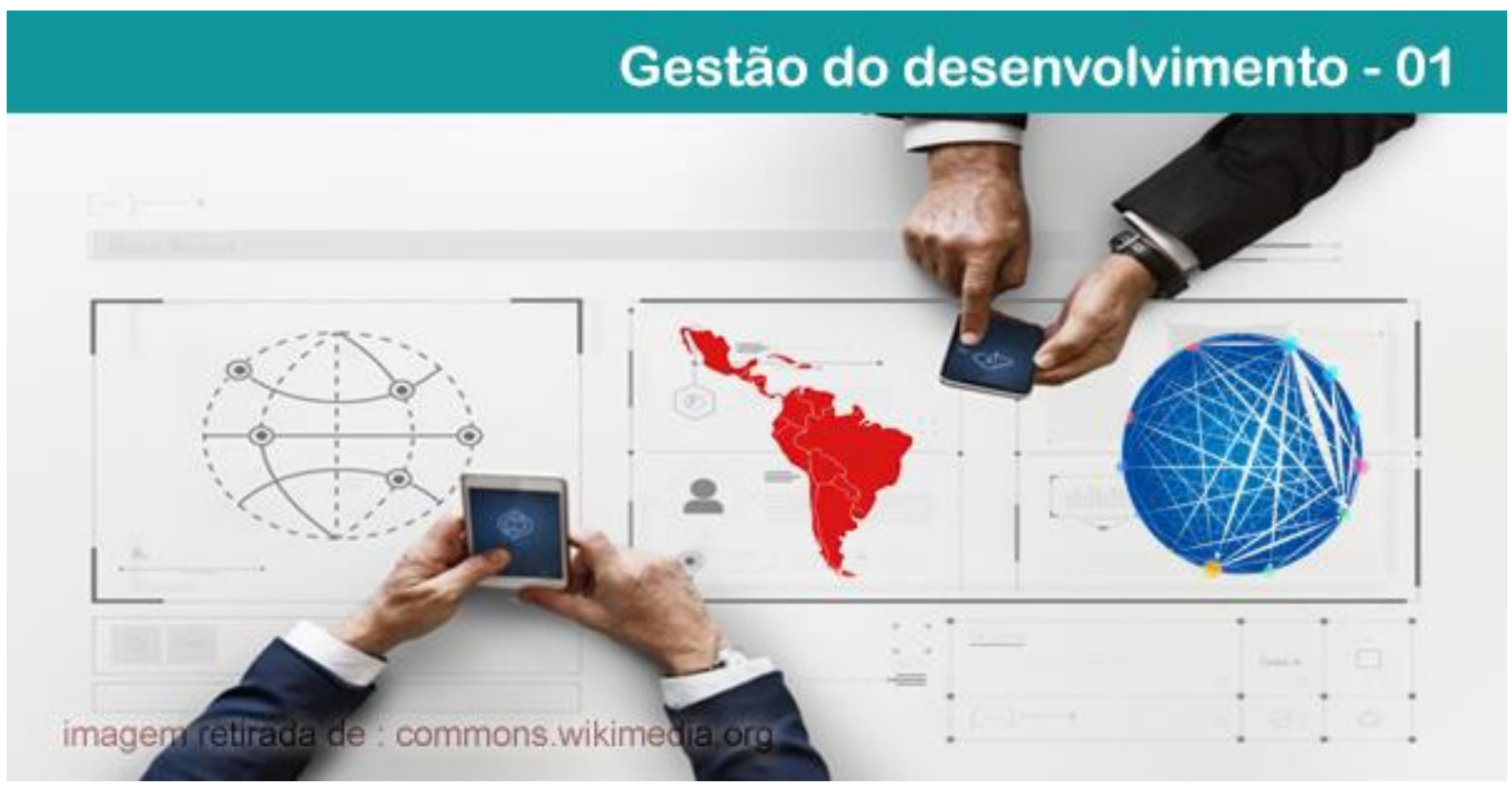

\title{
O PAPEL DAS UNIVERSIDADES EM SISTEMAS DE INOVAÇÃO EM CUBA E URUGUAI: REFLEXÕES PARA O CASO BRASILEIRO
}

\section{Israel Sanches Marcellino}

Mestre em Economia pela Universidade Federal Fluminense (UFF) e doutorando em Economia da Indústria e da Tecnologia pela Universidade Federal do Rio de Janeiro (UFRJ). Pesquisador vinculado à Rede de Pesquisas em Sistemas e Arranjos Produtivos e Inovativos Locais - RedeSist/UFRJ. Email: sanchesisrael@gmail.com.

\section{Elaine Cavalcante Peixoto Borin}

Professora da Faculdade de Engenharia da Universidade do Estado do Rio de Janeiro (UERJ). Doutora em Planejamento Urbano e Regional pela Universidade Federal do Rio de Janeiro (UFRJ). Pesquisadora da Rede de Pesquisa em Arranjos e Sistemas Produtivos e Inovativos Locais - RedeSist/UFRJ. E-mail: elaine.borin@ig.com.br.

Resumo: Reconhecendo a importância das especificidades de cada local, o objetivo deste trabalho é analisar o papel das universidades nos Sistemas de Inovação (SI), tendo os casos de Cuba e do Uruguai como estudo. A partir dessa análise, será possível destilar conceitos que proporcionem perspectivas úteis para a compreensão do caso brasileiro. O período atual traz novas dinâmicas ao sistema capitalista com desdobramentos para as lógicas da produção de conhecimento e da inovação. Logo, a emergência de um paradigma baseado em conhecimento e ciência, além das contradições impostas pelo processo de financeirização, tem posto em xeque o padrão tradicional de inserção das universidades nos SI. O avanço da financeirização sobre os orçamentos públicos em países como os da América Latina suscita questões relacionadas ao financiamento das universidades públicas. No esteio da lógica custo-benefício, surgem questões adicionais relacionadas ao impacto social e econômico efetivo das atividades universitárias. As universidades encontram-se compelidas a uma fase de transição em nível global. Essa transição, contudo, é um processo em andamento, pleno de incertezas e sem rumos únicos definidos.

Palavras-chave: Sistema de Inovação. Universidade. América Latina.

\section{THE ROLE OF UNIVERSITIES IN LATIN AMERICA INNOVATION SYSTEMS: REFLECTIONS ON THE CASES OF CUBA AND URUGUAY}

Abstract: Recognizing the importance of the specificities of each location, the aim of this paper is to analyze the role of universities in innovation systems (IS), taking as a study the case of Cuba and Uruguay. From this analysis,

\section{POLÊM!CA $\mid$ LABORE}

Polêmica - Revista Eletrônica da Uerj - Rua São Francisco Xavier, 524, $1^{\circ}$ andar bloco D, sl.1001 • Tels.: +55 21 2334-4088 / 4087 • http://www.e-publicacoes.uerj.br/index.php/polemica/index http://www.labore.uerj.br • laboreuerj@yahoo.com.br 
it will be possible to distill concepts that provide useful perspectives for understanding the Brazilian case. The present period brings new dynamics to the capitalist system with consequences for the logic of knowledge production and innovation. Thus, the emergence of a knowledge-based and science-based paradigm and the contradictions imposed by the financialization process have challenged the traditional pattern of insertion of universities in IS. The advancement of financialization over public budgets in countries such as Latin America raises questions related to the financing of public universities. Underlying the cost-benefit logic, additional questions arise regarding the effective social and economic impact of university activities. Universities are compelled to undergo a transitional phase at the global level. This transition, however, is an ongoing process, full of uncertainties and with no single defined directions.

Keywords: Innovation System. University. Latin America.

\section{Introdução}

Com a ascensão e consolidação do paradigma tecnoeconômico baseado nas tecnologias de informação e comunicação, o capitalismo ingressou em um período histórico marcado por diversas mudanças estruturais. Uma dessas mudanças se relaciona ao aprofundamento do significado econômico do conhecimento e dos processos de aprendizado (LUNDVALL; JOHNSON, 1994; 2016). Transformaram-se as maneiras como o conhecimento é criado, adquirido, gerenciado e difundido. De fato, na era do conhecimento, o aprendizado aprofunda seu papel no processo de inovação, constituindo-se como elemento crucial para a construção de capacitações, o fortalecimento de sistemas de inovação e para o desenvolvimento econômico.

Outra mudança foi o avanço da globalização dominada pelas finanças, que trouxe impactos significativos sobre a dinâmica capitalista com a emergência de um novo padrão de acumulação tecno-financeiro (CHESNAIS, 1996) e com rebatimentos sobre a dinâmica inovativa global. Segundo Lazonick e O’Sullivan (2000), o predomínio de elementos financeiros nas estratégias empresariais - maximizing shareholder value ideology $y^{1}$ - gera, entre outras consequências, uma tendência de redução nos investimentos em esforços inovativos de maior envergadura por parte de grandes empresas globais americanas. Ao mesmo tempo, mudanças institucionais na área de propriedade intelectual (principalmente o Bayh-Dole $\mathrm{Act}^{2} \mathrm{e}$ o Acordo TRIPs ${ }^{3}$ ) permitiram que o avanço da financeirização também se desse sobre

\footnotetext{
${ }^{1}$ Crença estabelecida na transição entre o século XX e o século XXI, principalmente nos Estados Unidos, de que priorizar a maximização do valor distribuído aos acionistas é princípio inerente à boa prática da governança corporativa, em detrimento da visão que associava a boa gestão ao crescimento do valor da empresa baseado na retenção de lucros para reinvestimento (ibid., p. 14).

${ }^{2}$ Lei estadunidense de 1980 que estabeleceu emendas à lei que versa sobre marcas e patentes naquele país. Entre outras mudanças, o Bayh-Dole Act ampliou as possibilidades de comercialização de propriedade intelectual, inclusive aquela resultante de projetos financiados com recursos públicos.

${ }^{3}$ Firmado em 1994, ao fim da rodada de negociações da OMC no Uruguai, este acordo possibilitou a estruturação de um sistema internacional de proteção à propriedade intelectual, convergindo com acordos multilaterais prévios e com grande aderência à legislação estadunidense.
}

\section{POLÊM!CA $\mid$ LABORE}

Polêmica - Revista Eletrônica da Uerj - Rua São Francisco Xavier, 524, $1^{\circ}$ andar bloco D, sl.1001 • Tels.: +55 21 2334-4088 / 4087 • http://www.e-publicacoes.uerj.br/index.php/polemica/index http://www.labore.uerj.br • laboreuerj@yahoo.com.br 
atividades de Pesquisa e Desenvolvimento (P\&D) e ativos como patentes, facilitando o bloqueio de trajetórias tecnológicas promissoras (ORSI; CORIAT, 2006).

Em suma, o período atual traz novas dinâmicas e tensões ao sistema capitalista com desdobramentos para as lógicas da produção de conhecimento e da inovação. Posto isso, a emergência de um paradigma baseado em conhecimento e ciência, além das contradições impostas pelo processo de financeirização, tem posto em xeque o padrão tradicional de inserção das universidades nos sistemas nacionais de inovação (SNI) (GÖRANSSON; BRUNDENIUS, 2011). Demandas crescentes sobre a produção de conhecimento afetam o direcionamento, o ritmo e os custos das atividades de pesquisa. Requerimentos por capacitações cada vez mais abrangentes, complexas e diversificadas afetam o ensino. A necessidade de difundir os resultados das atividades acadêmicas na sociedade, por sua vez, também pressionam as universidades em suas atividades de extensão.

Ademais dessas pressões, o avanço da financeirização sobre os orçamentos públicos em países como os da América Latina suscita questões relacionadas ao financiamento das universidades públicas. No esteio da lógica custo-benefício, surgem questões adicionais relacionadas ao impacto social e econômico efetivo das atividades universitárias.

Pode-se dizer, portanto, que as universidades encontram-se compelidas a uma fase de transição em nível global. Essa transição, contudo, é um processo em andamento, pleno de incertezas e sem rumos únicos definidos. Essas instituições - em cada sistema nacional de inovação - se defrontam com contextos heterogêneos, a partir dos quais as causas e os determinantes da transição acadêmica se manifestam de formas distintas. Isto é, a despeito de seus objetivos genericamente similares, a maneira como as universidades reagem às pressões sofridas dependem de fatores específicos às políticas, à sociedade e à economia dos territórios nos quais se encontram. Portanto, destarte, não se pode dizer que exista algo como um modelo ideal de universidade a ser perseguido globalmente. Ao contrário, é o contexto específico do sistema de inovação em que se inserem essas instituições que irá, ao mesmo tempo, delinear a forma como são sentidas essas pressões e determinar a maneira como as universidades devem reagir a elas.

As universidades se encontram em uma encruzilhada e a decisão sobre qual caminho seguir no futuro vem sendo alvo de políticas em diversos países da América Latina e do mundo (UNESCO, 2005; GÖRANSSON; BRUNDENIUS, 2011; BESLEY; PETERS, 2013; DUTRÉNIT Y NÚÑEZ, 2017). Reconhecendo a importância das especificidades de cada local,

\section{POLÊM!CA $\mid$ LABORÉ}

Polêmica - Revista Eletrônica da Uerj - Rua São Francisco Xavier, 524, $1^{\circ}$ andar

bloco D, sl.1001 • Tels.: +55 21 2334-4088 / 4087 • http://www.e-publicacoes.uerj.br/index.php/polemica/index http://www.labore.uerj.br • laboreuerj@yahoo.com.br 
o objetivo deste trabalho é analisar o papel das universidades nos SI, tendo como estudo o caso de Cuba e do Uruguai. A partir dessa análise, será possível destilar conceitos que proporcionem perspectivas úteis para a compreensão do caso brasileiro. As motivações do enfoque sobre esses dois países se alinham com a percepção que estudos para o caso brasileiro podem se beneficiar de avanços na reflexão de outros países latino-americanos. Evidentemente, não se ignoram as diferenças dos contextos de cada país, principalmente com relação à escala territorial e populacional e com relação à configuração sociopolítica de Brasil, Cuba e Uruguai. Contudo, ainda há outros pontos de convergência importantes entre os contextos desses países, em termos de inserção internacional, desafios para o desenvolvimento e quanto à condição periférica característica de toda a região.

\section{A visão tradicional sobre a Universidade na perspectiva de Sistemas de Inovação}

A abordagem de SI constitui um quadro de referência analítico que permite compreender a dinâmica inovativa de um país, região ou território (FREEMAN, 1987; COOKE, 1992; CASSIOLATO; LASTRES, 1999) ou mesmo de um setor (MALERBA; ORSENIGO, 1997). Essa perspectiva surgiu e se firmou entre as décadas de 1980 e 1990 a partir do amadurecimento da reflexão a respeito da inovação e sua natureza sistêmica. A inovação é vista como um processo social amplo que abarca uma miríade de atores e interações complexas. Portanto, um sistema de inovação pode ser entendido como um conjunto de organizações e instituições ${ }^{4}$ que interagem com o intuito de criar, difundir e aplicar conhecimentos de forma economicamente útil.

Segundo Cassiolato e Lastres (2005), a fundamentação da teoria de sistemas de inovação remete fortemente a evidências empíricas com destaque aos achados do Projeto Sappho (ROTHWELL et al., 1974) e da Yale Innovation Survey (KLEVORICK et al., 1995). Entre as diversas contribuições que essas pesquisas forneceram para o avanço da reflexão e da literatura, duas podem ser destacadas. As pesquisas do projeto Sappho buscaram na análise de projetos de inovação bem-sucedidos e malsucedidos de grandes empresas, a fim de distinguir os determinantes de sucesso e fracasso de tais intentos. A principal contribuição dessa pesquisa foi identificar, na interação com outros atores do que mais tarde veio a se chamar de sistema de

\footnotetext{
${ }^{4}$ Por exemplo: empresas, instituições de ensino e pesquisa, órgãos de política e fomento, organizações de financiamento, fornecedores, usuários, concorrentes, entre outros.
}

\section{POLÊM!CA $\mid$ LABORE}

Polêmica - Revista Eletrônica da Uerj - Rua São Francisco Xavier, 524, $1^{\circ}$ andar

bloco D, sl.1001 • Tels.: +55 21 2334-4088 / 4087 • http://www.e-publicacoes.uerj.br/index.php/polemica/index

http://www.labore.uerj.br • laboreuerj@yahoo.com.br 
inovação, um determinante crucial para o sucesso de projetos de inovação. Já nos esforços de pesquisa desenvolvidos em torno da Yale Innovation Survey, foram levados a cabo com o intuito de identificar as fontes das diferenças entre indústrias em termos de esforço inovativo e oportunidades tecnológicas. A principal contribuição, aqui, está na evidência de que a mobilização de fontes de conhecimento externas às firmas é essencial para a inovação.

Desde a década de 1980 até o período atual, a reflexão vem crescendo e se diversificando. Porém, pode-se dizer que há pelo menos três autores a quem se pode atribuir a formação de uma visão tradicional - algo próximo do canônico - de sistemas de inovação. São eles: Christopher Freeman (Inglaterra), Richard Nelson (Estados Unidos) e Bengt-Ake Lundvall (Dinamarca).

O primeiro a cunhar e utilizar o conceito, Freeman, conectou elementos da abordagem neoschumpeteriana com as ideias clássicas de List (1983), identificado com a escola histórica alemã, para delinear sua visão e aplicá-la ao caso do Sistema Nacional de Inovação (SNI) do Japão (FREEMAN, 1987). Sob essa perspectiva, a ênfase do autor se dá sobre os determinantes históricos que conformam instituições formais e informais do SNI e seus rebatimentos sobre a dinâmica inovativa e o desenvolvimento do país (FREEMAN, 1995). O foco se dá predominantemente sobre as instituições e sua história.

Outro autor de destaque na literatura neoschumpeteriana foi Nelson, que organizou sua visão de SNI a partir do caso estadunidense, buscando extrapolá-lo em uma ótica comparativa (NELSON, 1993). Aproximando-se mais da abordagem neoinstitucionalista, esse autor também enfocou as instituições, principalmente as científico-tecnológicas e os órgãos de política. Vale destacar que a tradição dessa linha da literatura não tem uma preocupação especial com as políticas de inovação implícitas, isto é, aquelas capazes de influir no desenvolvimento produtivo e inovativo sem estar direta e explicitamente voltadas a esse fim.

Por sua vez, Lundvall, observando a realidade do norte europeu, fornece outra variante daquilo que consideramos a visão clássica de SNI. A ênfase, para esse autor, está nas interações, principalmente entre produtores e usuários, como elemento decisivo para conferir a "sistematicidade" ao sistema de inovação (LUNDVALL, 1992).

A universidade, dentro dessa visão tradicional, cumpre um papel secundário diante das políticas públicas explícitas e as relações estabelecidas entre produtores e usuários. Segundo Klevorick et al. (1995), as universidades são apontadas como um tipo de ator importante para geração de conhecimento, contudo, não são vistas com um nível de protagonismo relevante,

\section{POLÊM!CA $\mid$ LABORÉ}

Polêmica - Revista Eletrônica da Uerj - Rua São Francisco Xavier, 524, $1^{\circ}$ andar

bloco D, sl.1001 • Tels.: +55 21 2334-4088 / 4087 • http://www.e-publicacoes.uerj.br/index.php/polemica/index http://www.labore.uerj.br • laboreuerj@yahoo.com.br 
tendo um papel mais passivo ao ter suas pesquisas monitoradas por empresas inovadoras. Seguem em direção semelhante Nelson e Rosenberg (1993), que entendem a P\&D como atividade inovativa de alta relevância e reconhecem nas universidades um espaço qualificado para a sua realização, com posterior apropriação dos resultados por parte de determinadas indústrias.

Transcendendo a realidade estadunidense, explorada por Nelson (1993) e seus pares, Freeman (1994) entende o papel da universidade na esfera da pesquisa como algo menor, uma vez que essa contribuição da pesquisa básica, quando relevante, é indireta. Na percepção desse autor, a principal função da universidade, em um sistema de inovação, dar-se-ia pela formação de recursos humanos com conhecimentos novos, impulsionando processos de construção de capacitação.

Por sua vez, Lundvall parte da abordagem da economia do aprendizado, a learning economy ${ }^{5}$ (LUNDVALL; JOHNSON, 1994), para colocar o aprendizado inovativo como o núcleo da lógica de funcionamento de um sistema de inovação. Desse argumento, desdobra-se a noção de que as universidades têm seu papel principal na formação de pessoas com competências, tais que sejam capazes de articular diferentes bases do conhecimento, para aplicá-las de maneira inovadora, e de interagir para aprender, acompanhando a dinâmica cada vez mais acelerada da era do conhecimento (LUNDVALL, 2002). Mais além, a dimensão da pesquisa, assim como para Freeman (1994), também teria impactos secundários na economia, uma vez que, para Lundvall (ibid., p.10), apenas alguns setores da indústria seriam capazes de se apropriar dos resultados da pesquisa acadêmica e gerar ganhos significativos. Neste ponto, o argumento sobre o papel da pesquisa universitária em um sistema de inovação está centrado na sua relevância para a educação superior, uma vez que guarda importantes sinergias com o aprendizado.

É nessa linha que Lundvall (2007 apud PARANHOS, 2010) consolida a percepção de que as universidades devem responder às pressões globais através de uma revolução acadêmica

\footnotetext{
${ }^{5}$ Conceito proposto pelos autores como alternativa à abordagem de economia do conhecimento (knowledge-based economy). A ideia básica da abordagem da economia da aprendizagem (learning economy) está no entendimento de que a celeridade do progresso técnico faz com que a capacidade de aprender e acessar novas bases de conhecimento é mais importante do que o próprio domínio efetivo sobre determinados tipos de conhecimento, conforme é pregado pela knowledge-based economy. Isso decorre do caráter amplo que a rapidez da mudança das tecnologias gera sobre diversos âmbitos, por exemplo: produção, trabalho, gestão, organização das empresas e das instituições, leis e normas. Logo, da mesma forma que conhecimentos novos emergem como importantes, estes podem se tornar obsoletos, fazendo com que a capacidade de aprender, isto é, assimilar novos conhecimentos, seja crucial no marco do atual paradigma tecnoeconômico.
}

\section{POLÊM!CA $\mid$ LABORÉ}

Polêmica - Revista Eletrônica da Uerj - Rua São Francisco Xavier, 524, $1^{\circ}$ andar bloco D, sl.1001 • Tels.: +55 21 2334-4088 / 4087 • http://www.e-publicacoes.uerj.br/index.php/polemica/index http://www.labore.uerj.br • laboreuerj@yahoo.com.br 
que intensifique sua contribuição para os processos de aprendizado interativo. A direção dessa mudança deveria se dar no sentido de ampliar a interação da universidade com os diversos segmentos da sociedade, principalmente as empresas, com o objetivo de qualificar o ensino e preservar a autonomia da pesquisa, dado seu valor pedagógico.

Um denominador comum entre essas visões daqueles que desenvolveram a abordagem tradicional de sistemas de inovação está o fato de observarem a realidade de regiões desenvolvidas (Japão, Escandinávia e EUA). Evidentemente, essa característica não torna menos válidas as conclusões alcançadas, mas gera noções, conceitos e prescrições de políticas mais adaptadas ao contexto dessas regiões. A questão do papel das universidades também é influenciada por esse viés, uma vez que a universidade subjacente à abordagem tradicional difere daquelas, por exemplo, da América Latina.

\section{A abordagem Latino-americana de Sistemas de Inovação}

O que se busca sublinhar aqui é que essa visão tradicional detalhada anteriormente se consolidou por autores do norte global a partir de análises aplicadas aos casos do norte global (AROCENA; SUTZ, 2003). A proposta de avançar sobre uma perspectiva do sul global, na qual se inclui a América Latina, constitui um avanço a medida que permite refinar os fundamentos conceituais e teóricos, de forma que se adapte melhor à realidade de países subdesenvolvidos.

Segundo Arocena e Sutz (2000), o olhar "sulista" demanda a qualificação de quatro aspectos do conceito de sistemas de inovação:

i) É considerado um conceito ex-post para os países industrializados avançados, uma vez que se desdobrou de investigações empíricas. Ao mesmo tempo, é um conceito exante para os países do sul global, pois precede as análises empíricas;

ii) O conceito leva uma carga normativa não adaptada à realidade do sul global e não necessariamente adequada, demandando cautela na mimetização acrítica de visões e ações;

iii) Trata-se de um conceito "relacional", embutindo as interações como elemento central para caracterizar um sistema enquanto tal. Para adaptar o conceito à realidade de países como os latino-americanos, é necessário flexibilizar essa noção, considerando-se

\section{POLÊM!CA $\mid$ LABORE}

Polêmica - Revista Eletrônica da Uerj - Rua São Francisco Xavier, 524, $1^{\circ}$ andar 
as interações e sua intensidade não como condição, mas como atributo da diversidade dos sistemas de inovação;

iv) Para além da capacidade descritiva e explicativa do conceito, a perspectiva de um país em desenvolvimento evoca, com força maior, a necessidade de se tratar o objeto de análise - o SNI - também como objeto de política.

Tendo em vista essas qualificações, o cerne dessa visão, desenvolvida para o sul global em geral e com especial atenção à América Latina, é adaptar o conceito de SNI às especificidades de países subdesenvolvidos. Primeiramente, ampliando a base empírica para a reflexão com vias à adaptação do conceito, os autores apontam a necessidade de incluir o tipo de inovação existente nesses países. No caso latino-americano, contam a formação econômica da região, na qual os sistemas agrícolas e agroindustriais são importantes, e a trajetória de industrialização. Além disso, cabe acrescentar evidências atuais, detalhando o tipo de inovação que ocorre nos tecidos produtivos desses países, quais os seus determinantes e quais os seus obstáculos.

Por último, cabe sublinhar a importância de aspectos relacionados ao contexto do ambiente nacional e a inserção internacional desses países. Tendo isso em vista, a contribuição de Cassiolato e Lastres (2008), permite identificar pontos de contato entre a abordagem latinoamericana de sistemas de inovação e o Estruturalismo latino-americano.

Dentre esses pontos, dois já foram comentados: a existência de assimetrias estruturais e de natureza tecnológica em países desenvolvidos e subdesenvolvidos e a importância das políticas para o desenvolvimento. Além disso, tanto a literatura de SNI quanto a escola estruturalista latino-americana chamam atenção para as especificidades de cada país, realçando a prevalência de fatores não econômicos.

Neste ponto, além da trajetória histórico-institucional, contam fatores de ordem cultural, política, geopolítica e social. Um exemplo de fator de ordem social é o alto nível de desigualdade na região, capaz de restringir a construção de estratégias de desenvolvimento mais inclusivas. Na esfera cultural, há a injustiça cognitiva (LASTRES; CASSIOLATO, 2016) que constitui uma tendência de privar grupos de interesses de sociedade do sul global de conceitos e ferramentas que proporcionem reflexões sobre suas realidades objetivas, criando obstáculos ao desenvolvimento de projetos e políticas voltados à afirmação da soberania nacional no contexto global.

\section{POLÊM!CA | LABORẸ}

Polêmica - Revista Eletrônica da Uerj - Rua São Francisco Xavier, 524, $1^{\circ}$ andar

bloco D, sl.1001 • Tels.: +55 21 2334-4088 / 4087 • http://www.e-publicacoes.uerj.br/index.php/polemica/index

http://www.labore.uerj.br • laboreuerj@yahoo.com.br 
Em termos geopolíticos, outro fator que dialoga com a dinâmica dos sistemas nacionais de inovação é a questão da inserção internacional, reforçando ou destruindo estruturas produtivas, tornando determinados tipos de políticas mais ou menos viáveis que outras e definindo o papel de empresas transnacionais. Considerando as políticas públicas, por último, reconhece-se para a América Latina, o papel fundamental das políticas implícitas como elemento inibidor da eficácia das políticas de desenvolvimento produtivo e inovativo (HERRERA, 1973).

Evidentemente, essas especificidades não só dialogam diretamente com o desenvolvimento das universidades na região, como sua inserção nos sistemas de inovação. No momento histórico atual de pressões globais sobre as universidades, a maneira como cada país busca dar respostas a essa problemática tem íntima relação com as características de cada SNI.

\section{Contribuições do debate sobre o papel das Universidades nos Sistemas de Inovação da} América Latina

\section{Uma visão cubana}

O SNI cubano se caracteriza por uma estrutura e por uma trajetória diferenciada, dado que se baseia em uma economia socialista. O país enfrentou uma crise profunda no início dos anos 90 com a perda do apoio de parceiros do leste europeu e com o acirramento da política estadunidense de imposição de restrições e embargo econômico. Esse período gerou iniciativas de reestruturação das políticas públicas no país com a finalidade de incluir na estratégia nacional elementos capazes de imprimir uma nova trajetória de desenvolvimento.

Conforme Núñez e Quiñones (2016), a reformulação estratégica ocorrida no final do século XX incorporou a noção de um sistema de inovação às iniciativas de política; e tem buscado sustentar uma mudança estrutural desde um padrão de especialização em gêneros primários para uma especialização em serviços de alto valor agregado. $\mathrm{O}$ espírito dessa abordagem confere papel de destaque às universidades cubanas, pensadas como vetor para o desenvolvimento produtivo e inovativo.

Vale notar que o país se caracteriza por um número bastante reduzido de empresas privadas com capacidade limitada para desempenhar atividades inovativas. Neste cenário, além das universidades, empresas públicas e instituições (principalmente o Ministério de Ciência, Tecnologia e Meio Ambiente) têm um papel decisivo no financiamento, orientação e realização

\section{POLÊM!CA | LABORÊ.}

Polêmica - Revista Eletrônica da Uerj - Rua São Francisco Xavier, 524, $1^{\circ}$ andar

bloco D, sl.1001 • Tels.: +55 21 2334-4088 / 4087 • http://www.e-publicacoes.uerj.br/index.php/polemica/index

http://www.labore.uerj.br • laboreuerj@yahoo.com.br 
de esforços de pesquisa e desenvolvimento. Neste arranjo institucional, o nível macro territorial da direção governamental encontra sua contraparte em nível micro territorial através da participação de atores vinculados à pesquisa, à produção, à inovação e ao desenvolvimento tecnológico, organizados em associações, fóruns e afins. A partir dessa estrutura e das políticas realizadas, se pretende avançar em prioridades definidas no plano nacional de desenvolvimento cubano que giram em torno de questões de infraestrutura (transporte e energia), meio ambiente (recursos hídricos) e necessidades sociais (alimentação, habitação e programas sociais incluindo saúde).

Considerando que a Revolução Cubana data do final da década de 1950, a preocupação em estabelecer o diálogo entre as políticas de desenvolvimento e as instituições de ensino e pesquisa remete aos idos do estabelecimento do governo revolucionário. Desde 1962, o sistema de educação superior cubano sofreu duas grandes reformas - chamadas de giros - e testemunha a terceira em curso. A primeira reforma, o giro à pesquisa transformou as universidades cubanas ao generalizar a pesquisa e viabilizou o início de um processo de acúmulo de capacitações. A segunda reforma, iniciada na década de 1980, promoveu o giro à inovação, e buscou orientar a pesquisa a objetivos práticos postos pelos desafios do setor produtivo ou pelas demandas sociais. A terceira reforma, iniciada no século XXI, é o giro territorial que busca expandir as universidades cubanas por todo o país, universalizando o acesso ao ensino superior e promovendo a articulação com o desenvolvimento local (NÚÑEZ; QUIÑONES, 2016).

O principal avanço logrado pelo giro territorial foi a criação dos Centros Universitários Municipais (CUM) nos 169 municípios cubanos. Os CUM reúnem as unidades acadêmicas de uma ou mais universidades presentes no município auxiliando na coordenação de atividades de acordo com diretrizes estratégicas definidas pelo Ministério de Educação Superior e com as necessidades específicas do território.

Esses centros funcionam, portanto, como pontes capazes de conectar as universidades com as orientações gerais da política pública e com as demandas dos diversos atores que compõem o território. Conforme Núñez e Quiñones (2016),

Os CUM devem atuar como eixo local aglutinador de patrimônio humano e inovativo da localidade e em algumas localidades conseguem atuar como agentes do conhecimento e da inovação. Trata-se de organizações bem situadas para captar as demandas sociais e articular os esforços de instituições com capacidade de transferir

\section{POLÊM!CA $\mid$ LABORE}

Polêmica - Revista Eletrônica da Uerj - Rua São Francisco Xavier, 524, $1^{\circ}$ andar bloco D, sl.1001 • Tels.: +55 21 2334-4088 / 4087 • http://www.e-publicacoes.uerj.br/index.php/polemica/index http://www.labore.uerj.br • laboreuerj@yahoo.com.br 
conhecimentos e tecnologias que gerem inovações de valor social. (NÚÑ̃EZ; QUIÑNONES, 2016, p. 200). ${ }^{6}$

Apesar de enfrentar dificuldades, o modelo cubano tem alcançado alguns êxitos, como na área de biotecnologia e em questões relacionadas à sustentabilidade socioambiental. Vale pontuar que as iniciativas descritas também enfrentam desafios, como na área de financiamento para importação de equipamentos de pesquisa.

A reflexão que norteia essa experiência agrega três eixos teóricos (ibid., 2016). O primeiro é a noção de desenvolvimento social inclusivo enquanto processo capaz de reduzir as desigualdades sociais e a pobreza das populações mais vulneráveis economicamente. Nesse tipo de desenvolvimento, o papel do progresso científico-tecnológico encontra espaço na noção de inovação social. O segundo é o conceito de sistema de inovação, com especial ênfase à abordagem de sistemas locais de inovação, ou APLs.

O terceiro eixo, decisivo para fechar o circuito lógico que conecta a atividade universitária ao desenvolvimento local, vem da sociologia da ciência através dos conceitos como o de trajetórias sociotécnicas e outras variantes. Trata-se de uma proposta de atualização dos conceitos tecnologia e de trajetória tecnológica (DOSI, 1984) a partir da incorporação conceitual dos determinantes sociais àqueles de natureza econômica convencionalmente considerados. Na raiz dessas concepções está a percepção que a tecnologia é mais do que a ciência aplicada.

Trata-se, portanto, da tecnologia de uma atividade humana que ocorre dentro de contextos sócio-históricos específicos, podendo abranger instrumentos ou práticas socialmente estabelecidas. Essa influência de determinantes sociais sobre a tecnologia leva à extrapolação da unidade analítica convencional (a empresa) enquanto núcleo de um sistema produtivo e inovativo, e se confere esse status de núcleo à sociedade em geral. Em sendo o território o ambiente onde esses laços sociais são estabelecidos de forma mais clara e sólida, tem-se como corolário a ideia que, assim como a inovação, a tecnologia é um elemento de natureza eminentemente local.

Dessa maneira, as universidades, enquanto instituições responsáveis por atividades de ensino e pesquisa, podem contribuir para o desenvolvimento tecnológico territorial ao gerenciar

${ }^{6}$ Tradução a partir do original em espanhol.

\section{POLÊM!CA $\mid$ LABORE}

Polêmica - Revista Eletrônica da Uerj - Rua São Francisco Xavier, 524, $1^{\circ}$ andar bloco D, sl.1001 • Tels.: +55 21 2334-4088 / 4087 • http://www.e-publicacoes.uerj.br/index.php/polemica/index http://www.labore.uerj.br • laboreuerj@yahoo.com.br 
o processo de criação e difusão de conhecimentos a partir das necessidades manifestas pelos atores que as circundam.

\section{$\underline{\text { Uma visão uruguaia }}$}

O Uruguai é um país pequeno, sendo 45 vezes menor que o Brasil em termos de extensão territorial e com apenas 3 milhões de habitantes, cerca de um quarto da população cubana. Essas dimensões reduzidas também se refletem na rede de ensino superior, concentrada em torno de uma única universidade (Universidad de la República - UdelaR) com um espectro pequeno de instituições de pesquisa públicas e privadas menores. De fato, nesse país, uma única universidade cumpre um papel central uma vez que, conforme Arocena e Sutz (2011), a UdelaR responde por algo em torno de $80 \%$ da produção científica uruguaia. Note-se que, neste caso, diferente da realidade da maioria dos países, mudanças institucionais em uma única universidade têm o potencial de gerar impactos significativos no sistema de inovação.

Nos tempos atuais, o país conta com uma base produtiva de produtos primários para exportação significativa. De maneira semelhante a outros países latino-americanos que passaram por experiências de industrialização, este processo ocorreu de forma que as empresas nacionais ocuparam os setores menos tecnologicamente dinâmicos enquanto os setores com dinâmica inovativa mais intensa foram ocupados por empresas transnacionais. Esse processo histórico moldou o SNI uruguaio com características típicas da região, no qual a demanda privada pelo conhecimento gerado pela universidade é estruturalmente fraca, uma vez que as transnacionais importam seus pacotes tecnológicos desde seus países de origem e as empresas nacionais, quando muito, demandam a universidade para serviços tecnológicos ou de consultoria (AROCENA; SUTZ, 2016).

É dentro desse contexto que se leva a cabo a experiência de reforma universitária no âmbito da UdelaR, realizada em paralelo a um esforço por parte do governo de implementação de um plano nacional de ciência, tecnologia e inovação, a reforma da universidade também se encaixou dentro de uma perspectiva de desenvolvimento inclusivo. Alinhado com o modelo de developmental university (BRUNDENIUS et al., 2009), o eixo norteador das ações foi ampliar as contribuições à sociedade das atividades de ensino, pesquisa e extensão com ênfase nos problemas sociais dos grupos mais vulneráveis (ALZUGARAY et al., 2013).

$\mathrm{Na}$ esfera do ensino, as mudanças buscaram dirimir o fenômeno do learning divide disparidade de aprendizagem -, entendido como a desigualdade resultante da assimetria nas

\section{POLÊM!CA $\mid$ LABORÉ}

Polêmica - Revista Eletrônica da Uerj - Rua São Francisco Xavier, 524, $1^{\circ}$ andar

bloco D, sl.1001 • Tels.: +55 21 2334-4088 / 4087 • http://www.e-publicacoes.uerj.br/index.php/polemica/index

http://www.labore.uerj.br • laboreuerj@yahoo.com.br 
oportunidades de aprendizado (AROCENA et al., 2018). Além disso, também se reconheceu a generalização do ensino superior como vetor de fortalecimento da democracia através da democratização conhecimento (AROCENA; SUTZ, 2013). Nas esferas da pesquisa e da extensão, a reforma procedeu de forma a buscar maior vinculação com a sociedade, formalizando sua integração no currículo acadêmico.

Outras mudanças estruturais ocorreram dentro da UdelaR, mas uma foi de particular interesse para o desafio de reorientar as atividades de pesquisa e extensão: a retomada e o aprimoramento do Programa de Investigación e Innovación Orientadas a la Inclusión Social. Conforme Alzugaray et al. (2013), o programa, em consonância com o cerne das propostas da reforma universitária, operava com chamadas públicas para financiar projetos de pesquisa ou de extensão capazes de solucionar problemas sociais. Entre 2008 e 2012, o programa acumulou menos projetos bem-sucedidos que projetos que não alcançaram seus objetivos. Contudo, observam os autores, a experiência do programa proporcionou alguns êxitos, como um aprendizado institucional durante as sucessivas melhorias no seu desenho chamada após chamada.

As dificuldades enfrentadas, contudo, foram de maior monta. A principal delas foi reconhecer os problemas sociais a serem alvo da ação por parte da universidade. Complementarmente, o reconhecimento dos próprios atores sociais a respeito dos problemas que sofrem também representou um obstáculo, não havia a articulação entre esses atores para demandar de forma organizada as ações da universidade. Um terceiro problema foi atribuído às métricas de avaliação acadêmica que, destoando do projeto de reforma da universidade, constituíram um conjunto de incentivos conflitantes com o programa, encorajando pesquisadores e professores a priorizar outras atividades que não aquelas pertinentes ao programa. Já o quarto problema remete à dificuldade de acessar canais que provenham capacidades produtivas ao projeto, como forma de viabilizar a introdução das inovações no mercado e sua difusão.

Esses desafios, por mais que diversos, convergem para um ponto em comum: a universidade, por si só, não parece ser capaz de criar redes, coordenar esforços internos e externos às firmas e criar sistemas de incentivos capazes de impulsionar as interações que necessita para inserir-se de forma mais virtuosa em um sistema de inovação. No caso do programa apresentado, as dificuldades, giraram em torno das dificuldades de articulação entre a política universitária e a política implícita (manutenção de mecanismos de avaliação

\section{POLÊM!CA | LABORÊ.}

Polêmica - Revista Eletrônica da Uerj - Rua São Francisco Xavier, 524, $1^{\circ}$ andar

bloco D, sl.1001 • Tels.: +55 21 2334-4088 / 4087 • http://www.e-publicacoes.uerj.br/index.php/polemica/index http://www.labore.uerj.br • laboreuerj@yahoo.com.br 
acadêmica), e dificuldades em se articular com diversos tipos de atores de fora da universidade. No entanto, reconhece-se que a criação de programas voltados à inclusão social e a ocorrência de projetos bem sucedidos a despeito dos obstáculos representam um ponto positivo e um caminho para a reflexão e o contínuo aprimoramento da prática.

\section{Considerações finais}

Para se extrair qualquer desdobramento dessas análises para o caso brasileiro, é necessário cautela com relação a algumas especificidades do ensino superior no Brasil. Primeiramente, o surgimento de universidades no SNI brasileiro foi tardio, já no início do século XX, enquanto as universidades mais antigas da América Espanhola datam do período colonial (SUZIGAN; ALBUQUERQUE, 2011). Essa demora contribuiu para que, por muitos anos, nosso sistema de ensino superior fosse relativamente atrasado ao lado de instituições mais amadurecidas e mais alinhadas com os princípios do Manifesto de Córdoba, de $1918^{7}$.

Em segundo lugar, há uma questão de escala. As instituições de ensino e pesquisa no Brasil buscam atender a uma sociedade significativamente mais populosa e dispersa no espaço de forma heterogênea. Seria difícil, por exemplo, justificar a razoabilidade e a viabilidade econômica de algo parecido com os CUM de Cuba nos 5.570 municípios brasileiros com populações que variam da ordem dos 10 milhões de habitantes, no caso da maior capital, para cidades com menos de mil habitantes, como certos territórios do interior. Ao mesmo tempo, medidas que contribuam para impedir o avanço do learning divide, como a expansão das universidades feita no escopo da Reestruturação e Expansão das Universidades Federais (REUNI), são necessárias.

Passa portanto que, da mesma maneira que não se deve buscar nos modelos de universidade do norte global um benchmark a ser imitado, essa postura tampouco se justifica para os modelos de outros países latino-americanos. Porém, ao contrário desses primeiros, os últimos fornecem pistas mais relevantes de como lidar com as pressões de transição sobre as universidades brasileiras, dado o maior nível de similaridade entre os sistemas nacionais de inovação.

\footnotetext{
${ }^{7}$ O manifesto La juventud argentina de Córdoba: A los hombres libres de Sud América (A juventude argentina de Córdoba: Aos homens livres da América do Sul), redigido e assinado por alguns dos dirigentes da Federação Universitária de Córdoba ficou conhecido como o Manifesto de Córdoba de 1918. A publicação desse manifesto é uma expressão da luta estudantil que teve como consequência a implementação da reforma universitária exigida pelos estudantes na ocupação da Universidade de Córdoba.
}

\section{POLÊM!CA $\mid$ LABORÉ}

Polêmica - Revista Eletrônica da Uerj - Rua São Francisco Xavier, 524, $1^{\circ}$ andar

bloco D, sl.1001 • Tels.: +55 21 2334-4088 / 4087 • http://www.e-publicacoes.uerj.br/index.php/polemica/index

http://www.labore.uerj.br • laboreuerj@yahoo.com.br 
As duas experiências, e as literaturas que com elas dialogam, destacam: o desenvolvimento territorial (para o caso cubano) e a preocupação com as necessidades sociais de grupos vulneráveis (para o caso uruguaio). Em ambos os casos, a universidade é concebida como agente capaz de influenciar ativamente a dinâmica de um sistema de inovação e o processo de desenvolvimento. Cabe a ressalva, contudo, que essa capacidade de agir tem sua eficácia comprometida quando feita de forma isolada, dependendo a universidade da articulação com outros atores do sistema de inovação para alcançar seus objetivos.

No caso brasileiro, a abordagem cubana converge com a perspectiva de APL e é útil para avançar no sentido inverso. No "giro territorial" a abordagem de APL é mobilizada para delinear o papel das universidades. É possível observar experiências de APLs brasileiros como forma de entender a maneira como neles se inserem as universidades e levantar questionamentos sobre que tipos de mudanças seriam capazes de tornar essa inserção mais efetiva. Um caminho para se avançar nessa linha de pesquisa seria incorporar a dimensão social da tecnologia, permitindo ver canais através dos quais uma universidade pode aprofundar sua relação com a sociedade no território.

$\mathrm{Na}$ literatura uruguaia, a dimensão territorial é secundária. $\mathrm{O}$ topo das prioridades se coloca nas demandas sociais. Ao considerar uma perspectiva de desenvolvimento incompatível com os altos níveis de desigualdade social, o modelo da developmental university propõe que uma fragilidade de um SNI como o brasileiro seja mobilizado como demanda estratégica para a construção de capacitações e o aprendizado. Esse esforço não necessariamente exclui estratégias de enraizamento das universidades no território, nem representa obstáculo essencial a outros tipos de estratégia de desenvolvimento tecnológico e industrial.

Dentro da lógica de APLs, a perspectiva da developmental university é potencialmente útil para entender as maneiras como a universidade deve desenvolver essa conexão com o território e suas demandas, pois propõe o conceito de autonomia conectada. Mais além, um ponto fundamental colocado nessa literatura é a influência dos sistemas de avaliação de desempenho acadêmico sobre as atividades universitárias. Este ponto, se incorporado como elemento de análise, é potencialmente útil para explicar certos padrões de inserção de instituições de ensino e pesquisa em APLs.

\section{POLÊM!CA $\mid$ LABORE}

Polêmica - Revista Eletrônica da Uerj - Rua São Francisco Xavier, 524, $1^{\circ}$ andar bloco D, sl.1001 • Tels.: +55 21 2334-4088 / 4087 • http://www.e-publicacoes.uerj.br/index.php/polemica/index http://www.labore.uerj.br • laboreuerj@yahoo.com.br 


\section{Referências}

AROCENA, R.; SUTZ, J. Looking at National Systems of Innovation from the South. Industry and Innovation, Londres, v. 7, n. 1, p. 55-75, jan. 2000.

Knowledge, innovation and learning: systems and policies in the north and in the south. In: CASSIOLATO, J.; LASTRES, H.; MACIEL, M. (Ed.). Systems of Innovation and Development: Evidence from Brazil. Rio de Janeiro: Edward Elgar, 2003.

Uruguay: Higher Education, National System of Innovation, and Economic Development in a small peripheral country. In: GÖRANSSON, B.; BRUNDENIUS, C. (Ed.). Universities in Transition: The changing role and challenges for academic institutions. Nova York: Springer, 2011.

Innovación y Democratización del conocimiento como contribución al desarrollo inclusivo. In.: DUTRÉNIT, G.; SUTZ, J. (Org.). Sistemas de Innovación para un Desarrollo Inclusivo: La experiencia latinoamericana. Cidade do México: Editora Foro Consultivo Científico y Tecnológico, 2013.

Universidades para el Desarrollo. Montevideo: UNESCO, 2016.

AROCENA, R.; GÖRANSSON, B.; SUTZ, J. Developmental Universities in inclusive innovation systems. Genebra: Palgrave Macmillan, 2018.

AZUGARAY, S.; GOÑI, M.; MEDEROS, L.; ROBAINA, S. Políticas de Conocimiento para un Desarrollo Inclusivo: Aprendizajes desde Uruguay. In: DUTRÉNIT, G.; SUTZ, J. (Org.). Sistemas de Innovación para un Desarrollo Inclusivo: La experiencia latinoamericana. Cidade do México: Editora Foro Consultivo Científico y Tecnológico, 2013.

BESLEY, T.; PETERS, M. Re-imagining the Creative University for the 21st century. Rotterdam: Sense Publishers, 2013.

BRUNDENIUS, C.; LUNDVALL, B.; SUTZ, J. The role of universities in innovation systems in developing countries: developmental university systems - empirical, analytical and normative perspectives. In.: LUNDVALL, B.; JOSEPH, K.; CHAMINADE, C.; VANG, J. (Org.). The Handbook of Innovation Systems and Developing Countries: Building domestic capabilities in a global setting. Cheltenhan: Elgar, 2009.

CASSIOLATO, J.; LASTRES, H. (Org.). Globalização e inovação localizada: experiências de sistemas locais no Mercosul. 1. ed. Brasília: IBICT, 1999.

Sistema de Inovação e Desenvolvimento: as implicações de política. São Paulo em Perspectiva, São Paulo, v. 19, n. 1, p, 34-45, jan./mar. 2005.

Discussing innovation and development: converging points be-tween the Latin American school and the innovation systems perspective. Globelics Working Papers Series, Aalborg, v. 2, n. 2, jan. 2008.

CHESNAIS, F. A Mundialização do Capital. São Paulo: Xamã, 1996.

COOKE, P. Regional innovation systems: competitive regulation in the new Europe. GeoForum, Cambridge, v. 23, n. 3, p. 365-382, jul./set. 1992.

DOSI, G. Technical change and industrial transformation. London: Macmillan, 1984.

DUTRÉNIT, G.; NÚÑEZ, J. Vinculación universidad-sector productivo para fortalecer los sistemas nacionales de innovación: experiencias de Cuba, México y Costa Rica. La Habana: Editorial UH, 2017.

FREEMAN, C. Technology Policy and Economic Performance: Lessons from Japan. London: Pinter Publishers, 1987.

\section{POLÊM!CA $\mid$ LABORE}

Polêmica - Revista Eletrônica da Uerj - Rua São Francisco Xavier, 524, $1^{\circ}$ andar bloco D, sl.1001 • Tels.: +55 21 2334-4088 / 4087 • http://www.e-publicacoes.uerj.br/index.php/polemica/index http://www.labore.uerj.br • laboreuerj@yahoo.com.br 
FREEMAN, C. The economics of technical change. Cambridge Journal of Economics, Cambridge, v. 18, n. 18, p. 463-514, out. 1994.

. The 'National System of Innovation' in historical perspective. Cambridge Journal of Economics, Cambridge, v. 19, n. 1, p. 5-24, fev. 1995.

GÖRANSSON, B.; BRUNDENIUS, C. (Ed.). Universities in Transition: The changing role and challenges for academic institutions. Nova York: Springer, 2011

HERRERA, A. Los determinantes sociales de la política científica en América Latina - política científica explícita y política científica implícita. Desarrollo Económico, Córdoba, v. 13, n. 49, abr./jun. 1973.

KLEVORICK, A. K.; LEVIN, R.; NELSON, R.; WINTER, S. On the sources and significance of inter-industry differences in technological opportunities. Research Policy, Londres, v. 24, n. 2, p. 185-205, mar. 1995.

LASTRES, H.; CASSIOLATO, J. Novos referenciais analíticos e de política: Experiências com o desenvolvimento do enfoque em arranjos produtivos e inovativos locais. In.: NÚÑ̃Z, J.; QUIÑONES, A (Org.). Universidad y desarrollo local: contribuciones latinoamericanas. Cidade do México: Editorial Universitária Felix Varela, 2016.

LAZONICK, W.; O’SULLIVAN, M. Maximizing Shareholder Value: A New Ideology for Corporate Governance. Economy and Society, Londres, v. 29, n. 1, p. 13-35, jan. 2000.

LIST, F. Sistema Nacional de Economia Política. São Paulo: Editora Abril, 1983

LUNDVALL, B. (Ed.). National Innovation Systems: Towards a Theory of Innovation and Interactive Learning. London: Pinter Publishers, 1992.

The university in the learning economy. DRUID Working Paper, Copenhage, v. 1, n. 6, jan. 2002.

LUNDVALL, B; JOHNSON, B. The learning economy. Journal of Industry Studies, Londres, v. 1, n. 2, p. 2342, jun./dez. 1994.

The Learning Economy. In: LUNDVALL, B. (Ed.) The Learning Economy and the Economics of Hope. Londres: Anthem Press, 2016.

MALERBA, F.; ORSENIGO, L. Technological Regimes and Sectoral Patterns of Innovative Activities. Industrial and Corporate Change, Nova York, v. 6, n. 1, jan. 1997.

NELSON, R. (Ed.). National innovation systems: a comparative analysis. Nova York: Oxford University Press, 1993.

NELSON, R.; ROSENBERG, N. Technical Innovation and national systems. In.: NELSON, R. (Ed.). National innovation systems: a comparative analysis. Nova York: Oxford University Press, 1993.

NÚÑEZ, J.; QUIÑONES, A. (Org.). Universidad y desarrollo local: contribuciones latinoamericanas. Cidade do México: Félix Varela, 2016.

ORSI, F.; CORIAT, B. The New Role and Status of Intellectual Property Rights in Contemporary Capitalism. Competition \& Change, Londres, v. 10, n. 2, p. 162-179, jun. 2006.

PARANHOS, J. Interação entre empresas e instituições de ciência e tecnologia no sistema farmacêutico de inovação brasileiro: estrutura, conteúdo e dinâmica. 2010. 327 f. Tese (Doutorado em Economia) - Instituto de Economia, Universidade Federal do Rio de Janeiro, 2010.

ROTHWELL, R.; FREEMAN, C.; HORSLEY, A.; JERVIS, P.; ROBERTSON, A.; TOWNSEND, J. SAPPHO Updated - Project SAPPHO Phase II, Research Policy, Londres, v. 3, n. 3, p. 258-291, nov. 1974.

\section{POLÊM!CA $\mid$ LABORE}

Polêmica - Revista Eletrônica da Uerj - Rua São Francisco Xavier, 524, $1^{\circ}$ andar

bloco D, sl.1001 • Tels.: +55 21 2334-4088 / 4087 • http://www.e-publicacoes.uerj.br/index.php/polemica/index http://www.labore.uerj.br • laboreuerj@yahoo.com.br 
SUTZ, J.; AROCENA, R.; BRUNDENIUS, C. Universities in Innovation Systems: Conectedness and Alternative Research Evaluation Metrics. In: 15th GLOBELICS CONFERENCE, Athens, Greece, 2017.

SUZIGAN, W.; ALBUQUERQUE, E. M. A interação entre universidades e empresas em perspectiva histórica no Brasil. In: SUZIGAN, W.; ALBUQUERQUE, E. M.; CARIO, S. A. F. (Org.). Em busca da inovação: interação universidade-empresa no Brasil. São Paulo: Autêntica, 2011.

UNESCO. United Nations Decade of Education for Sustainable Development (2005-2014): International Implementation Scheme. United Nations Educational, Scientific and Cultural Organization (UNESCO), Paris, France, 2005.

Recebido em: 01/03/2019.

Aceito em: 30/03/2019.

\section{POLÊM!CA $\mid$ LABORE}

